\title{
Robot As Virtual Learning Object
}

\author{
Vinícius Ferreira da Silva Bianchi Grilo* \\ *Departamento de Elétrica e Eletrônica, Centro Federal de Educação Tecnológica de Minas \\ Gerais, Leopoldina, Brazil. \\ E-mail: ferreira_vinicius@icloud.com \\ Paulo Pinheiro Junqueira \\ •Departamento de Elétrica e Eletrônica, Centro Federal de Educação Tecnológica de Minas \\ Gerais, Leopoldina, Brazil. \\ E-mail: pauloppj@hotmail.com \\ Fabiano Pereira Bhering \\ `Departamento de Elétrica e Eletrônica, Centro Federal de Educação Tecnológica de Minas \\ Gerais, Leopoldina, Brazil. \\ E-mail: fabianobhering@leopoldina.cefetmg.br \\ Lindolpho Oliveira de Araújo Júnior` \\ 'Departamento de Elétrica e Eletrônica, Centro Federal de Educação Tecnológica de Minas \\ Gerais, Leopoldina, Brazil. \\ E-mail: lindolpho@leopoldina.cefetmg.br
}

\begin{abstract}
Nowadays it is notorious that technology is part of our life, and it is being drastically evolving along the years. New forms of audiovisual medias are constantly being develop, nevertheless teaching methods still reaming the same as the ones that were approached before the advances of technology. These new technologies could transform the way we teach by creating interactive platforms in practical disciplines offered in technical and Engineering courses that would not only improve the quality of teaching but also would enhance students learning process and reduce costs of laboratories.
\end{abstract}


In this context, this work aims to present an alternative resource in the area, a virtual learning object and virtual laboratory with remote access that increases quality of classes by creating an immersive experience that is close to reality, and allows students to actually interact and test the knowledge acquired. The main goal was to provide remote access to the automation laboratory and to safely execute practical experiments. To being with, an environment consisting of a 3D model of the ARM7220-4 robot arm was developed, containing the majority of the robot movement functions as well as mechanical, geometric and kinematic of the real robot arm, and granting its access through Moodle platform to students of Centro Federal de Educação Tecnológica de Minas Gerais (CEFET-MG), Campus Leopoldina. The hardware, are composed by a real robot ARM-7220-4 that is connect to the virtual tool, and responds to the commands sent by the student through the virtual environment, and a camera is also connected, allowing the real-time monitoring of the physical laboratory. To evaluate the work, a teaching practice was proposed, consisting on movement of the robotic arm through tasks on order to validate the knowledge acquired through bibliographic didact sources, addressing theoretical aspects. Final results of the experiments with students from the campus that have tested the complete system showed that the learning object is a promising resource for distance learning courses.

Keywords: Remote Access, Virtual Lab, Virtual Learning Environment, Virtual Learning Objects, Engineering Education.

\section{Introduction}

The technologies of audiovisual communication are increasingly present in our daily life. However, they are still insufficient explored in educational institutions.

Because students are already familiar with receiving interactive information across multiple platforms in their homes, these same technologies could be very useful for performing practical activities required to complement the theoretical content offered by the teacher.

The use of new educational tools such as projectors and touch-sensitive frames has brought more interactivity to classrooms, but they still do not offer an immersive experience in which the student can actually interact and test the acquired knowledge.

Many institutions, mainly Engineering courses, also lack of physical and financial resources to match to all students' needs, and many of them do not even have labs to carry out specific activities.

A virtual learning environment becomes an interesting approach to contribute to new experiences, such as to provide students with a greater involvement with practical activities, inserting virtual objects, similar to real laboratories that arouse the sensation of being physically performing practical and collaborative activities ${ }^{1}$. Thus, institutions that do not have sufficient resources to meet the demand of students and teachers can use more modern and interactive methods for teaching and learning with a low investment.

\section{Related Work}

Normally, Robotics Education is carried out in real laboratories using computers with specific software, such as RoboDK ${ }^{2}$, RobCAD ${ }^{3}$ and V-REP ${ }^{4}$, to program the robot's operations. The program is simulated in the software and can be transferred to the robot controller for execution in real environment.

A teaching approach based on Teach Pedant ${ }^{5}$, proposes the use of online programming technique, in which a robot remains operational while the program is developed and executed in its controllers. In this case, the programming is done based on the points or trajectories 
that the robot must follow. The required data is collected by robot controllers during the teaching process. Teaching is usually done using a portable robotic terminal called teach pendant, which provides convenient means to move the robot, teach locations and execute programming according to the robot's joints. Most robot manufacturers provide their own teach pedant for their industrial robots. The teach pedant can be used to teach Robotics for beginners as it does not require programming skills. However, the high cost of configuring the equipment makes it impossible to deploy real laboratories.

One of the proposed solutions to this problem is the use of a remote laboratory using the concepts of tele-robotics ${ }^{6,7}$. These platforms provide teach pedant emulation in the form of a GUI that is used to remotely program real robots and also to view the manipulator movements through a webcam. The RoboLab application proposes a virtual and remote laboratory for teaching Robotics, using a joystick to define the movement of the virtual robot ${ }^{8,9}$. In addition, a smartphone-based teach pedant to control a virtual robot was proposed by ${ }^{10}$. The Hammer application ${ }^{11}$ has a tablet-based graphical interface for programming industrial robots and comes with virtual teach pedant features that can be used to simulate robot movements.

The presented work do not offer an integration of the learning object to the learning management system. Thus, the differential of this proposal is to relate the virtual laboratory to the practical and theoretical classes offered by Moodle, besides offering an immersive environment as a means of communication between students and teachers ${ }^{12,13}$.

\section{Purpose}

This paper presents a virtual learning object for use in Engineering courses, with a proposal to create a 3D virtual laboratory in which students and teachers interact in an immersive environment.

The virtual environment is an alternative to both teaching theory and teaching in practice, with the possibility of visualizing the interaction of a real robot through the control of a virtual robot.

By accessing the virtual object, the student can develop laboratory activities provided by professors and available through Moodle platform ${ }^{14}$, and also control real equipment without being present, besides that, bringing to the institution a new technological resource to improve the practical quality in teaching of Engineering.

\section{Design}

For the development of the application, three main procedures were conducted. These consist of: ARM-7220-4 robotic arm modeling, server implementation and system integration with the Moodle platform.

\subsection{Robotic Arm Modeling ARM-7220-4}

For this stage of development, a software called Blender was used, in which the 3D model necessary for the operation of the environment were made. The robotic arm model consists of five joints, in addition to actuating claw. The Figure 1 shows the modelling part in Blender software. 


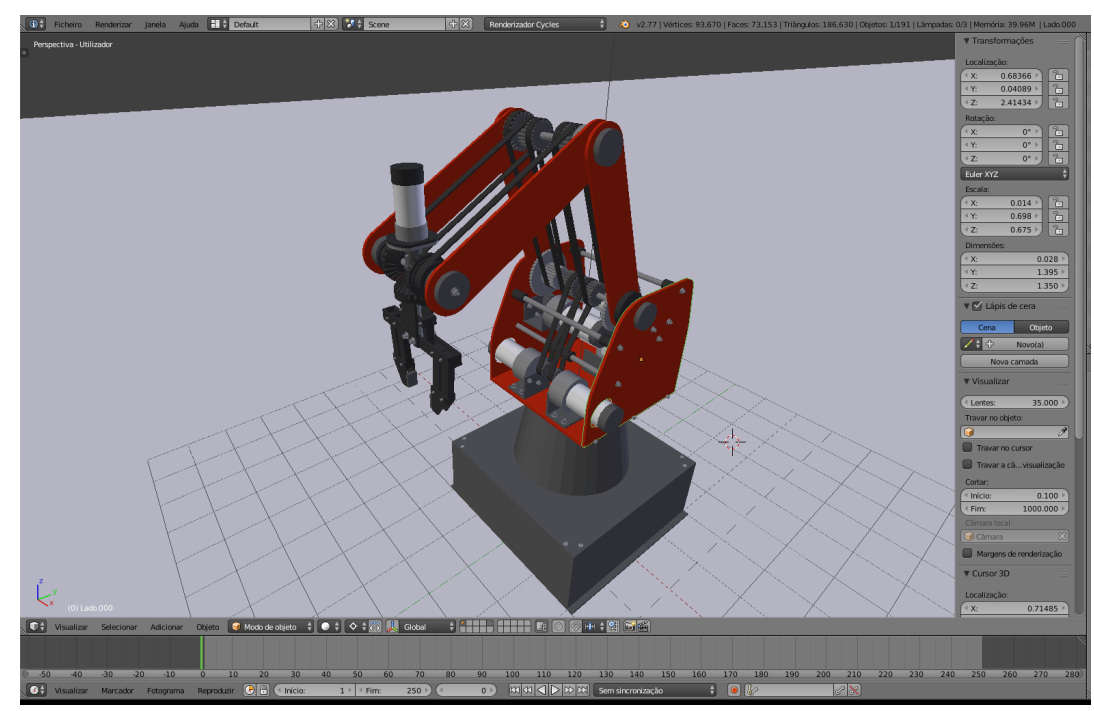

Figure 1. 3D Modeling of the model.

The kinematics functions were implemented using Unity 3D software, which enabled the user to enter data referring to the movement of the robot joints. Thus, six fields were provided for the user to interact with the simulation. Consist of:

- Waist: responsible for the movement of the base, or similar to the human body, a shoulder;

- Shoulder: responsible for moving the robot arm;

- Elbow: responsible for the movement of the robot's forearm;

- Pitch: responsible for angular movement of the actuator or claw;

- Roll: responsible for the rotation movement of the claw; and

- Claw: responsible for opening or closing the claw.

Those parameters, that are available to the user, can be seen in the lower right corner of the Figure 2.

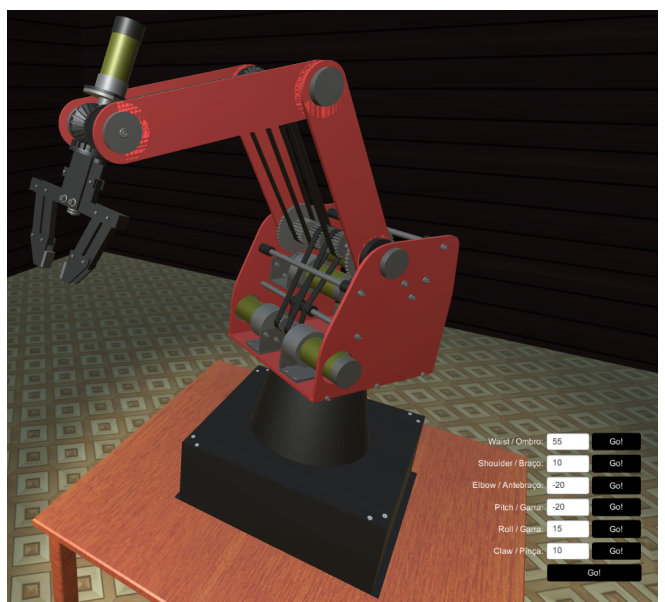

Figure 2. Developed environment and manipulation functions. 


\subsection{Server Implementation}

For the development of the proposed system, it was necessary to implement a server to aid the communication between the student and the real robot. Thus, it was developed using TCP/IP communication through a PHP application. This server is responsible for receiving commands from the user, interpreting them and performing real robot control. In addition, it is transmitted to the student the image captured in real time by a camera that is positioned in the direction of the robotic arm. Therefore, allowing access to the robot through the $3 \mathrm{D}$ environment.

\subsection{Integration of the system with the Moodle platform}

In order to facilitate the use of the environment, integration with Moodle distance learning environment was established. So, it is possible to access via web the theoretical content developed by the professor, besides allowing access to the platform.

The SCORM tool was used to connect the 3D environment to the Moodle platform. SCORM is a package consisting of animations, 3D models, images and others that allow the application to run completely. In Figure 3, it is possible to observe the scheme of the whole structure of the system that was explained.

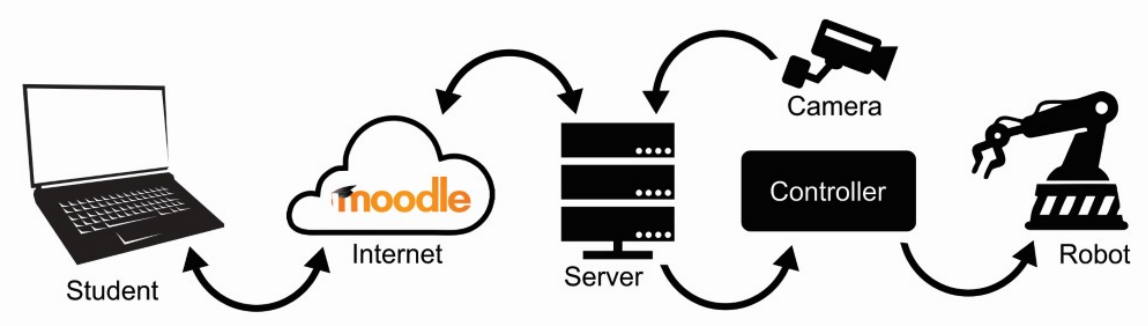

Figure 3. Structure of the system.

\section{Results}

For the evaluation of the virtual laboratory, students of Control and Automation Engineering course of CEFET-MG, Leopoldina campus were invited to test the learning object. The students had to complete a few activities that were developed to simulate laboratory activities. They were proposed to positioning the virtual robotic arm into specific locations by changing the parameters of each component of movement. After learning in the virtual environment, they were able to control the real equipment, that was connected in real time with the simulation. Figure 4, shows the simultaneous activities during the experiment. The students who were invited to test the learning object, filled in a questionnaire about their experience.

Among the questions asked in the questionnaire, it is possible to point that the results showed that only $23 \%$ of the students had participated in distance learning courses or had contact with other types of virtual learning object, indicating that distance learning courses have a really good potential to grow. Moreover, about $86 \%$ of the students had never used other virtual object in studies before and about $75 \%$ of them showed great interest in working with the virtual object. Some of the questions can be seen in the Figure 5. Most 
of the students considered themselves with a good knowledge in Robotics and had a great interest in the subject.
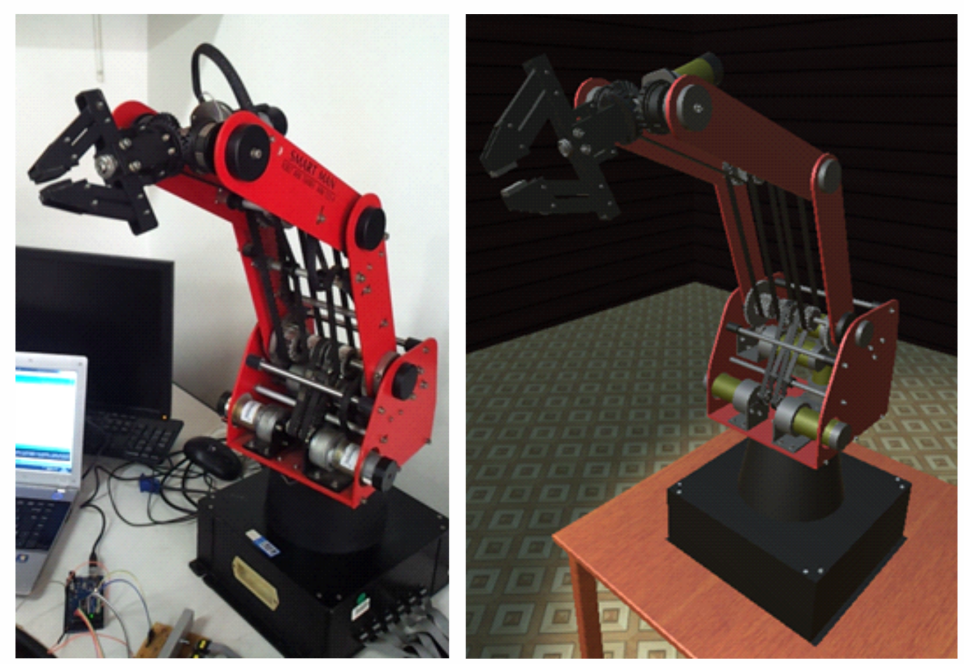

Figure 4. Simultaneous control during students' activities.

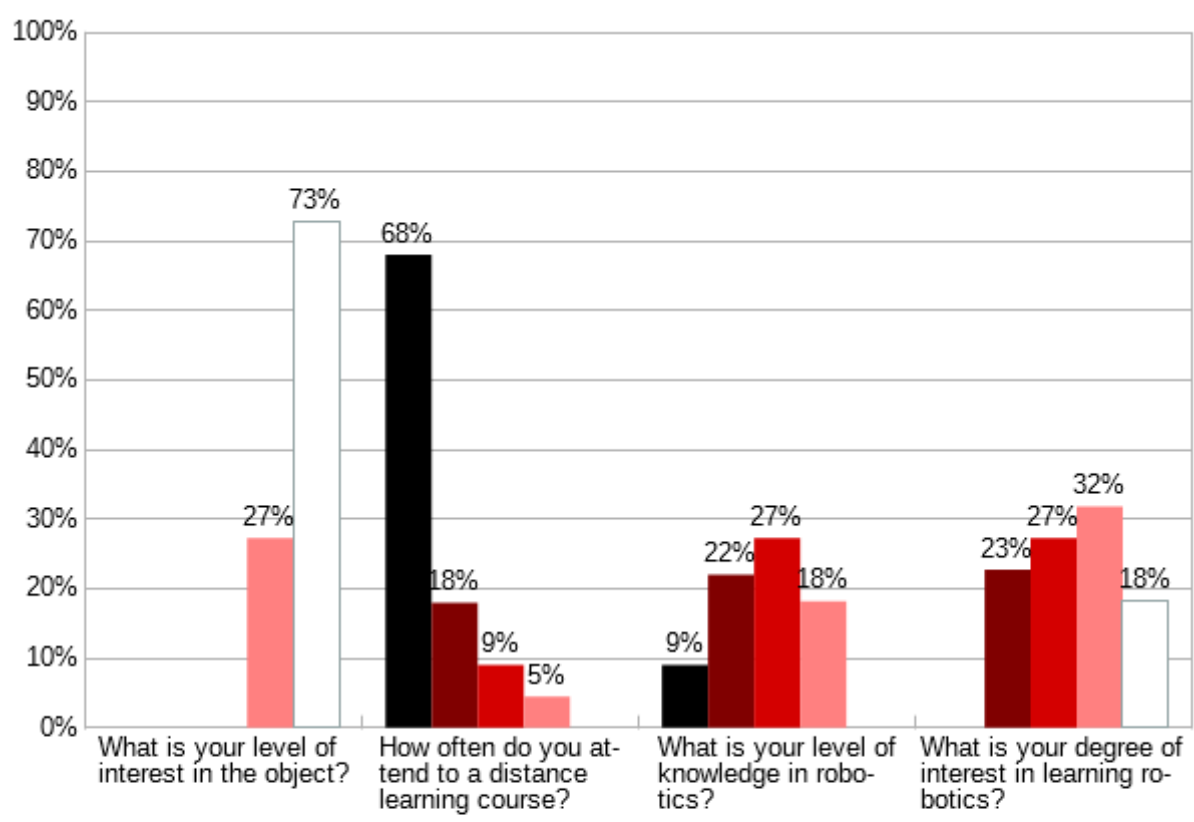

- None $\quad$ Low $\quad$ Moderate $\quad$ Decent $\quad \square$ Great Interest

Figure 5. Answers to the questionnaire applied to the students.

All the students that participated in the project greatly enjoyed the experience of working with the virtual robotic arm and would like it to be integrated into other activities as 
well. Moreover, all of them approved the use of the new teaching object and confirmed that it can be essential to encourage and help learning.

\section{Conclusions}

The implementation of a virtual laboratory with remote access gives students a great immersion and interactivity with learning objects, as well as facilitate the accomplishment of practical activities in the disciplines of the Engineering course. This paper presents a proposal for a $3 \mathrm{D}$ virtual laboratory integrated into Moodle that can be replicated in remote simulation of laboratory experiments, granting institutions that do not have such equipment to use them, requiring or not supervision for the activities, since it reduces the risk of damaging the equipment or hurting students. In addition, creating mechanisms for the interaction between virtual and real equipment.

The virtual environment was offered to Engineering students who positively evaluated the learning resource, indicating a new opportunity for the construction of increasingly interactive educational tools.

\section{Acknowledgment}

We would like to express our deepest appreciation to all those who provided the possibility to complete this work. A special gratitude we give to CEFET-MG, CNPq, $\mathrm{MEC} / \mathrm{SESu} / \mathrm{PET}$ and FNDE for their support in this project.

\section{Reference}

1. VALENTE, J. A. Blended learning e as mudanças no ensino superior: a proposta da sala de aula invertida. Educar em Revista (2014): p.79-97.

2. BIMBRAW, I. M. K.; CHITTAWADIGI, R. G.; SAHA, S. K. A teach pendant to control virtual robots in Roboanalyzer. In: INTERNATIONAL CONFERENCE ON ROBOTICS AND AUTOMATION FOR HUMANITARIAN APPLICATIONS (RAHA), 2016, Kollam, p. 1-6.

3. ROBODK, Simulation and OLP for Robots. Available: <http://www.robodk.com $>$. Accessed on: 6 June 2017.

4. SIMENS INDUSTRIAL SOFTWARE, Robotics and automation workcell simulation, validation and off-line programmin - RoboCAD, Available in: $<$ https://www.plm.automation.siemens.com/en/products/tecnomatix/manufacturingsimulation/robotics/robcad.shtml>. Accessed on: 6 June 2017.

5. COPPELIA ROBOTICS, Virtual Robot Experimentation Platform. Available: $<$ http://www.coppeliarobotics.com $>$. Accessed on: 6 June 2017.

6. TZAFESTAS, C. S.; PALAIOLOGOU, N.; ALIFRAGIS, M. Virtual and remote robotic laboratory: comparative experimental evaluation. IEEE Trans. on Education, v. 49, n. 3, p. 360-369, Aug. 2006.

7. PARKIN, R. M. Control of robot arm with virtual environment via the internet. Proc. of the IEEE, v. 91, n. 3, p. 422-429, Mar. 2003.

8. TORRES, F.; CANDELAS, F. A.; PUEnTE, S. T.; POMARES, J.; GIL, P.; ORTIZ, F. G. Experiences with virtual environment and remote laboratory for teaching and learning robotics at the university of Alicante. International Journal of Engineering Education, v. 22, n. 4, Aug. 2006.

9. CANDELAS, F. A.; BRAVO, C. A. J.; MEDINA, F. T. Flexible virtual and remote laboratory for teaching Robotics. In: CURRENT DEVELOPMENTS IN TECHNOLOGY-ASSISTED EDUCATION, 2006. 
64 ISSN: 2358-1271. Int. J. of Alive Eng. Educ. (IJAEEdu). (Online). Goiânia, v. 4, n. 2, p. 57-64, July/Dec. 2017.

10. JAN, Y.; HASSAN, S.; PYO, S.; YOON, J. Smartphone Based Control Architecture of Teaching Pendant for Industrial Manipulators. In: INTERNATIONAL CONFERENCE ON INTELLIGENT SYSTEMS MODELLING \& SIMULATION IEEE, 4., 2013. Proceedings..., 2013.

11. MATEO, C.; BRUNETE, A.; GAMBAO, E.; HERNANDO, M. Hammer: An Android based application for end-user industrial robot programming. In: INTERNATIONAL CONFERENCE ON MECHATRONIC AND EMBEDDED SYSTEMS AND APPLICATIONS IEEE/ASME, 10., 2014. Proceedings..., 2014.

12. LIVINGSTONE, D.; JEREMY, K. Integrating web-based and 3D learning environments: Second Life meets Moodle. CEPIS UPGRADE: European Journal for the Informatics Professional 2008.3 (2008): p. 8-14.

13. NORTON, T. Learning C\# by Developing Games with Unity 3D. Packt Publishing Ltd, 2013.

14. CRAIG, J. Introduction to robotics: mechanics and control. Pearson Prentice Hall, 2005. 